\title{
A high-accuracy trajectory following controller for pneumatic devices
}

\section{J. Falcão Carneiro \& F. Gomes de Almeida}

The International Journal of Advanced Manufacturing Technology

ISSN 0268-3768

Volume 61

Combined 1-4

Int J Adv Manuf Technol (2012)

61:253-267

DOI 10.1007/s00170-011-3695-6

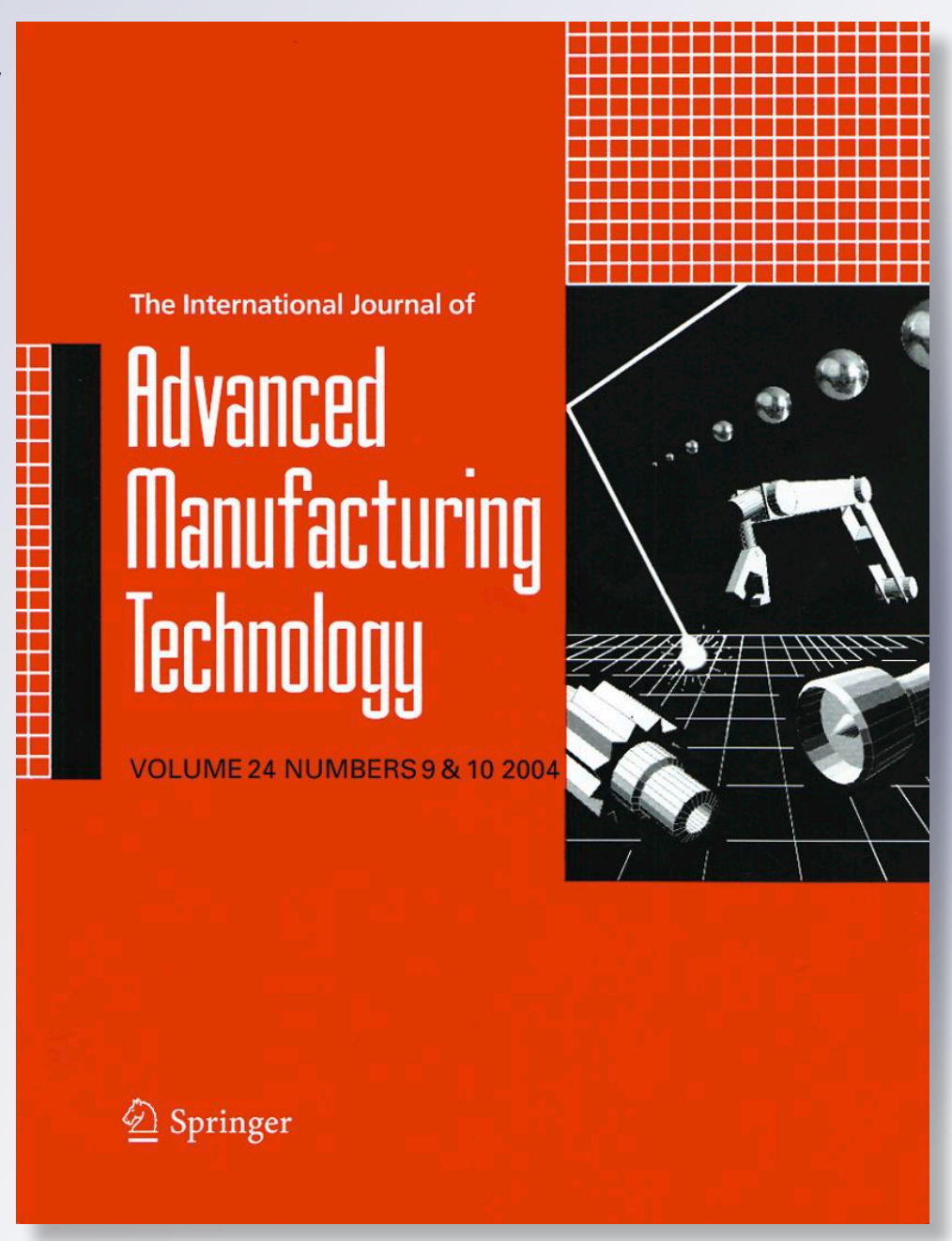

望 Springer 
Your article is protected by copyright and all rights are held exclusively by Springer-Verlag London Limited. This e-offprint is for personal use only and shall not be self-archived in electronic repositories. If you wish to selfarchive your work, please use the accepted author's version for posting to your own website or your institution's repository. You may further deposit the accepted author's version on a funder's repository at a funder's request, provided it is not made publicly available until 12 months after publication. 


\title{
A high-accuracy trajectory following controller for pneumatic devices
}

\author{
J. Falcão Carneiro • F. Gomes de Almeida
}

Received: 30 June 2011 / Accepted: 10 October 2011 / Published online: 1 November 2011

(C) Springer-Verlag London Limited 2011

\begin{abstract}
The use of pneumatic devices is widespread among different industrial fields, in tasks like handling or assembly. Pneumatic systems are low-cost, reliable, and compact solutions. However, its use is typically restricted to simple tasks due to the poor performance achieved in applications where accurate motion control is required. This paper presents a novel nonlinear controller, using neural network-based models, that allows the use of common industrial servopneumatic components in applications where fine trajectory following tasks is required. Furthermore, several experimental trials show that the system is highly robust to payload variation without any controller retuning. These results encourage the use of pneumatics actuators in a set of applications for which they have not been traditionally considered.
\end{abstract}

Keywords Servopneumatic systems · Trajectory following industrial tasks · Artificial neural networks · Nonlinear control

\section{Introduction}

Pneumatic devices are inexpensive, clean, do not overheat, do not produce magnetic fields, and present a high power to weight ratio. Furthermore, pneumatic energy is readily available in most manufacturing facilities. Despite these facts, pneumatic systems are seldom used in applications where fine motion control is needed, like for example

J. F. Carneiro $(\bowtie) \cdot$ F. G. de Almeida

IDMEC, Faculdade de Engenharia, Universidade do Porto,

Rua Dr. Roberto Frias, s/n,

4200-465, Porto, Portugal

e-mail: jpbrfc@fe.up.pt welding, robotic manipulation, or fluid injection. This is caused by the highly nonlinear behavior of pneumatic systems that makes them very difficult to model and control. The evolution in computer processing of recent decades endorsed the possibility of applying highly evolved nonlinear control and modeling techniques to servopneumatics. This factor along with the appearance of certain applications for which pneumatic systems are a natural choice gave rise to a refreshed interest of researchers around the world on this subject. For instance, in [1], Kagawa et al. describe an application where the fast and fine positioning of semiconductor wafers must be obtained in an environment without electromagnetic fields or excessive heat generation. These requirements are naturally fulfilled by pneumatic actuators.

There are several challenging problems in servopneumatic systems modeling. For instance, the model of a servovalve can be developed to be used in valve design and online monitoring of valve operating conditions [2] or more dedicated to control purposes [3-6]. Regarding the mechanical model, friction is perhaps the most challenging task. The control engineer is usually faced with a difficult tradeoff: how to balance the simplicity required to synthesize the control law while maintaining the complexity necessary for a realistic friction description. Several studies in literature can be found, ranging from the simple, static, Karnopp friction model [7], to the more complex, dynamic, Lugre model [8] and its evolutions [9].

The model of each pneumatic chamber can be obtained using thermodynamic laws and is a second-order model with temperature and pressure as state variables [10]. This model is usually simplified by neglecting the temperature dynamics and considering a polytropic process. Guidelines on which reduced order model to use can be found in [11]. It is also possible to find in literature studies with a high level of detail in mechanical modeling. For instance, the 
model developed in [12] accounts for the end of stroke cylinder cushioning and the model developed in [10] accounts for the connecting tube pressure dynamics.

Very different control strategies, ranging from classical PID [13] to fuzzy logic [14], are used to handle servopneumatic systems challenges. One of the most used control strategies is state feedback. It is possible to find studies using linear state feedback since the 1980s $([15,16])$ up until more recently [17]. Nonlinear state feedback techniques [18, 19] have also been applied to servopneumatics for instance by Richard and Scavarda in [3] and, more recently, by Richard and Outbib [20]. This technique can also be found in a recent study by Xiang and Wikander [21] where excellent experimental results are reported in positioning tasks. Despite this fact, it is not possible to find in [21] either trajectory following results or robustness tests to parametric changes. Other interesting control techniques also applied to servopneumatics are gain scheduling techniques $[22,23]$ and adaptive control [24-27].

In order to cope with the high uncertainty of pneumatic system modeling, several studies use variable structure controllers (VSC) [19]. For instance, Drakunov et al. [28] developed an interesting control architecture that integrates different techniques for the mechanical and the pressure dynamics: a VSC controller is used for the pressure dynamics and a nonlinear state feedback is used for the mechanical dynamics. Other studies using VSC controllers where developed by Pandian et al. in [29] and by Richer and Hurmuzlu in [30]. It is also possible to find applications of high-order sliding mode controllers [31] in pneumatics, for example in the study developed by Smaoui et al. in [32].

Another approach that has been tested in servopneumatic systems is the use of artificial neural networks (ANN) and fuzzy logic-based control [14]. For instance, in [33], Junbo et al. developed a controller that is an online-trained threelayer ANN with a non-conventional training algorithm also developed in [33]. This study has also an interesting particularity: the valves attached to the cylinder are proportional pressure-reducing valves. In a more recent study, Lee et al. [34] use ANN to compensate friction effects, in a similar way to the one followed in the present work. Sinusoidal position references with different amplitudes ( 30 to $70 \mathrm{~mm}$ ) and frequencies $(0.1 \mathrm{and} 0.5 \mathrm{~Hz})$ are used to test the performance of the controlled system. The maximum tracking error is found to be between 6 and $16 \mathrm{~mm}$.

The costs associated with servovalves can be reduced by using less expensive ON/OFF valves [23]. In [35] this approach was applied to a pneumatic system comprising a double-acting cylinder and two ON/OFF valves with $5 \mathrm{~ms}$ switching time. The control law is a PID with friction compensation. The reported experimental results are very interesting since that even with a sixfold mass variation the trajectory following error is below $2 \mathrm{~mm}$. In another work [36], one of the strategies proposed in [35] is enhanced and tested in a vertically mounted pneumatic actuator. Although faster valves are used in [36] (2 ms switching time), results are worse than those obtained in [35], namely a maximum error of about $4 \mathrm{~mm}$ when following a ramp reference.

In most of the above described studies the errors in trajectory following tasks are of a few millimeters and heavily depend on the load. In the present work, an innovative servopneumatic device is presented that can achieve an error below $1 \mathrm{~mm}$, without any controller retuning, when following variable frequency sinusoids with loads ranging from 2.69 to $13.1 \mathrm{~kg}$.

This paper is organized as follows. In Section 2 the experimental setup is described and its complete model presented. Section 3 is dedicated to the presentation of an innovative nonlinear controller which is subsequently tested in Section 4. Finally, Section 5 discusses the main conclusions drawn from this work.

\section{Servopneumatic system}

\subsection{Experimental setup}

The experimental setup used in this work includes two subsystems: (1) the data acquisition and control hardware/ software and (2) the electropneumatic components. The data acquisition and control system comprises a PC with data acquisition boards and all the hardware/software needed for signal conditioning. The electropneumatic system presented in Fig. 1 includes an air treatment unit, two servovalves, a pneumatic actuator driving the carriage of a monorail guideway, two pressure transducers, an accelerometer and a

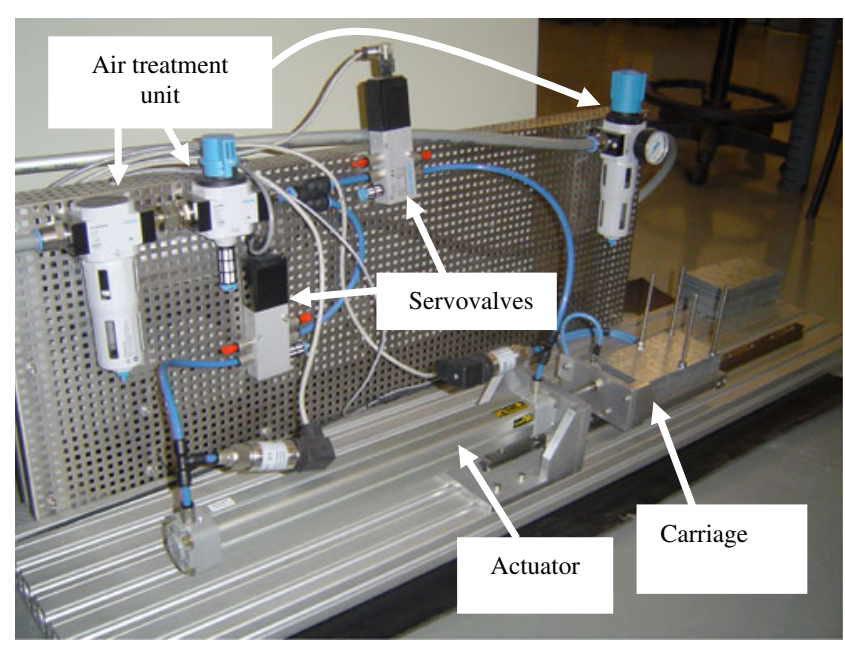

Fig. 1 Experimental setup 
position encoder integrated in the guidance system. The encoder is manufactured by Rexroth, has a resolution of $5 \mu \mathrm{m}$ and an accuracy of $\pm 30 \mu \mathrm{m}$. The pneumatic actuator is manufactured by Asco-Joucomatic and has a stroke length of $400 \mathrm{~mm}$, a piston diameter $\phi=32 \mathrm{~mm}$ and a rod diameter $\phi_{\mathrm{h}}=16 \mathrm{~mm}$. Both servovalves are manufactured by Festo (MPYE-5-1/8-HF-010-B), are used as three-orifice valves and have a nominal mass flow of $700 \mathrm{slpm}$. Table 1 resumes the main system parameters.

\subsection{System model}

Figure 2 presents a schematic representation of the pneumatic servosystem where $P, T, V$, and $A$ represent pressure, temperature, volume, and area of each chamber, respectively. The moving mass $M$ can be changed from 2.69 to $13.1 \mathrm{~kg}$ and the source pressure $P_{\mathrm{s}}$ is set at $P_{\mathrm{s}}=$ 7 bar. The mass of air flowing into/from each chamber ( $\dot{m}_{\mathrm{A}}$ and $\dot{m}_{\mathrm{B}}$ ) is modulated by two servovalves A and B by varying the control action $u_{\mathrm{A}}$ and $u_{\mathrm{B}}$, respectively. Notice that although the use of a single five-orifice servovalve is more common in pneumatic literature (see for instance [10, $28,30]$ ), considering two servovalves allows an extra degree of freedom that can be exploited to enhance the performance of the system, as it will be presented in Section 3.2.

The analysis of the mathematical model of this system reveals three main blocks (see Fig. 3): the servovalves, the actuator chambers, and the motion model.

\subsubsection{Servovalves}

Consider the three-orifice servovalve represented in Fig. 4. The port connected to chamber A or chamber B of the pneumatic actuator is called the work port, port $\mathrm{S}$ is connected to the pressure source and port $\mathrm{M}$ to atmosphere. $x_{\mathrm{v}}(u)$ is the valve moving spool position and $u$ is the command input.

Assuming that (1) the variations of the cylinder chambers temperature with respect to ambient temperature are negligible, (2) the pressure source is at ambient temperature, and (3) that ambient pressure, ambient temperature, and source pressure only suffer small deviations from their nominal values, the mass flow through the work port can be written as: $[3,5,6$, 37]

$\dot{m}=\varphi\left(u, P, P_{\mathrm{atm}}, P_{\mathrm{s}}, T_{\mathrm{amb}}\right) \approx \varphi(u, P)$

The knowledge of $\varphi$ therefore establishes a direct model of the servovalve: given the working pressure $P$ and the command input $u$, the mass flow crossing the work orifice can be determined. Conversely, for a given pressure $P$, the function $\varphi^{-1}$ defined in (2) must exist since the relation between $u$ and $\dot{m}$ is biunivoque under normal working conditions $\left(P_{\mathrm{atm}} \leq P \leq P_{\mathrm{s}}\right)$.

$u=\varphi^{-1}(\dot{m}, P)$

The knowledge of $\varphi^{-1}$ allows the use of Eq. 2 to determine an inverse model of the servovalve: the controller of the system provides a desired mass flow and given the working pressure $P$, the inverse model delivers $u$ so that $\dot{m}$ is achieved. It is important to mention that the assumption of a constant supply pressure is consistent with common servopneumatic practice since an air accumulator is typically inserted in the circuit feeding line. Furthermore, this assumption avoids an extra degree of freedom in Eqs. 1 and 2 , making the mapping of $\varphi$ and $\varphi^{-1}$ less complex. In [5] and [6], artificial neural networks were used to approximate $\varphi$ and $\varphi^{-1}$, leading to a direct artificial neural network (DANN) and an inverse artificial neural network (IANN) model as presented in Eqs. 3 and 4.

$\dot{m}_{\mathrm{A}, \mathrm{B}}=\operatorname{DANN}\left(u_{\mathrm{A}, \mathrm{B}}, P_{\mathrm{A}, \mathrm{B}}\right)$

$u_{\mathrm{A}, \mathrm{B}}=\operatorname{IANN}\left(\dot{m}_{\mathrm{A}, \mathrm{B}}, P_{\mathrm{A}, \mathrm{B}}\right)$

In this work the interest is focused on IANN since it provides the servovalve inverse model that will be used to determine the control action. This network is a fully connected multilayer perceptron (MLP) with three layers: the first one has 10 hyperbolic tangent sigmoid - tansig, see Eq. 5-neurons, the second one has six tansig neurons and

Table 1 System parameters

\begin{tabular}{llllll}
\hline Actuator & & & Servovalves \\
\hline Manufacturer & Stroke $l$ & Piston diameter $\phi$ & Rod diameter $\phi_{\mathrm{h}}$ & Reference & Nominal maximum mass flow \\
Asco-Joucomatic & $0.4 \mathrm{~m}$ & $32 \mathrm{~mm}$ & $16 \mathrm{~mm}$ & FESTO MPYE-5-1/8-HF-010-B & $700 \mathrm{slpm}$ \\
\hline
\end{tabular}


Fig. 2 Pneumatic servosystem schematic representation

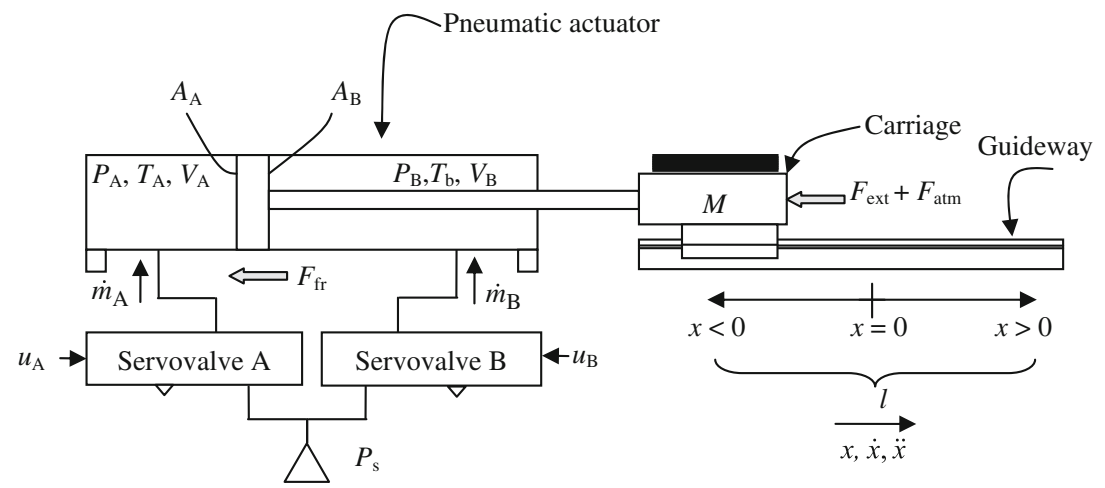

the third has one linear neuron. For background on multilayer perceptrons the reader is referred to [38].

$\operatorname{tansig}(\alpha)=2 /\left(1+\mathrm{e}^{-2 \alpha}\right)-1$

As explained in detail in [5, 6] and [37], by using (4) the system model can be written in an affine form, thus enabling the use of some advanced nonlinear control techniques like the ones used in this work (sliding mode control and nonlinear state feedback). A detailed description of the procedures used to obtain experimental data and of the network training is beyond the scope of this paper and is provided in [5, 6] and [37].

\subsubsection{Actuator model}

The actuator model can be divided into two parts: the mechanical model, comprising pneumatic, inertia, and friction forces, and the thermodynamic model that describes pressure evolution inside the chambers of the pneumatic cylinder. The mechanical model can be obtained by applying Newton's second law to the system in Fig. 2:

$\ddot{x}=\frac{F_{\mathrm{p}}-F_{\mathrm{fr}}-F_{\mathrm{ext}}}{M}$

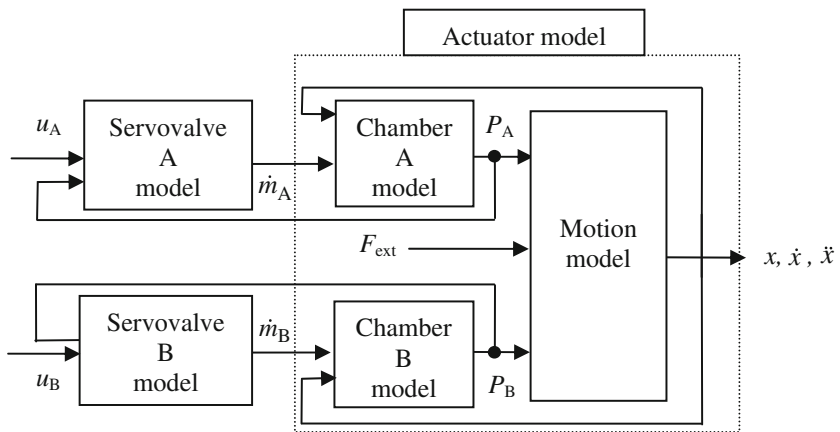

Fig. 3 Block models of a pneumatic system controlled with two three orifices servovalves where $F_{\mathrm{fr}}$ and $F_{\text {ext }}$ are friction and external forces, respectively, and

$F_{\mathrm{p}}=P_{\mathrm{A}} A_{\mathrm{A}}-P_{\mathrm{B}} A_{\mathrm{B}}-F_{\mathrm{atm}}$

is the available pneumatic force with $F_{\mathrm{atm}}=P_{\mathrm{atm}}\left(A_{\mathrm{A}}-A_{\mathrm{B}}\right)$. In this work it is considered that there are not any external forces acting on the cylinder, so $F_{\text {ext }}=0$. The friction model is provided by an offline trained artificial neural network, denominated FANN, whose inputs are the piston velocity and acceleration:

$\widehat{F}_{\text {fr }}=\operatorname{FANN}(\dot{x}, \ddot{x})$

The FANN network is a fully connected MLP with three layers having 10 tansig, six tansig, and one linear neuron, respectively.

As presented in [11], the thermodynamic model describing temperature and pressure evolution inside a pneumatic cylinder chamber comprises two differential equations with temperature and pressure as state variables. This is inappropriate for control purposes since it is mathematically difficult to handle and demands a mass or temperature observer as these variables cannot be correctly measured during operation.

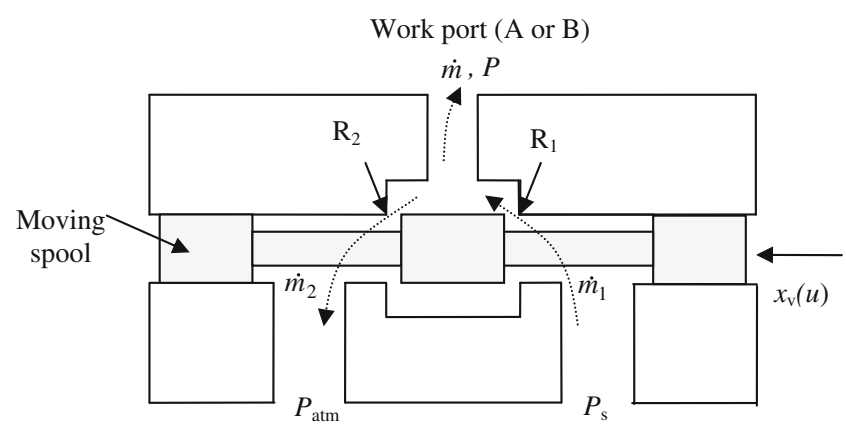

Port M

Port S

Fig. 4 Schematic representation of a three-orifice servovalve 
Due to these reasons, the thermodynamic model is usually simplified, leading to reduced order models. Temperature is the natural state variable to remove since force and motion state directly depend on pressure (see Eq. 6).

This work will use the results obtained in [11], where a comparison study between several reduced order models existing in literature and some new ones was performed. The model given by Eqs. 9 and 10 with $n=1.35$ was selected as the best model in [11], and will consequently be used in this work to describe the evolution of pressure inside each chamber. The value of the heat transfer conductance $k_{0}$ was experimentally determined using the procedure presented in [39].

$T=T_{0}\left(\frac{P}{P_{0}}\right)^{\frac{n-1}{n}}$

$\frac{d P}{d t}=-\gamma \frac{P}{V} \frac{d V}{d t}+\gamma \frac{R}{V} T\left(\dot{m}_{\text {in }}-\dot{m}_{\text {out }}\right)-\frac{\gamma-1}{V} k_{0}\left(T-T_{\text {amb }}\right)$

\section{Nonlinear controller}

The block diagram presented in Fig. 5 describes the controller architecture developed in this work. Given a trajectory reference $\left(x_{\text {ref }}, \dot{x}_{\text {ref }}, \ddot{x}_{\text {ref }}\right)$ and the friction force estimate $\widehat{F}_{\text {fr }}$ given by (8), the motion controller provides a pneumatic force reference $F_{\text {pref. }}$. Since two servovalves are used, the choice on how to determine each chamber force reference $\left(F_{\text {Aref }}\right.$ and $F_{\text {Bref }}$, see (11)) is made by a force division block. Both force controllers provide a desired mass flow reference which is then input to the inverse model of the servovalves to determine the control actionsee previous section.

$F_{\text {pref }}=F_{\text {Aref }}-F_{\text {Bref }}-P_{\text {atm }}\left(A_{\mathrm{A}}-A_{\mathrm{B}}\right)$
This control structure presents several innovations. First, the separation between force and motion control allows the use of adequate control laws for each of them. In fact, motion dynamics require a robust control law as there is high uncertainty due to load variation and friction modeling errors. On the contrary, the force dynamic model is less uncertain due to the work developed in [11] and [39], so a more modeldependent control law can be used, like the nonlinear state feedback (NSF) presented in the next section. This allows for velocity effects on force dynamics to be explicitly accounted for (cf. Section 3.1), leading to a higher bandwidth force control. Notice that this is an original control architecture although other researchers have also separated motion and force control [21], [28]. In fact, in [21] an NSF-based strategy has been used in both controllers while in [28] the strategy followed was somehow inverse to the one followed in this work: motion control was NSF based and force control was VSC based. Another unique feature of this controller relies on the force division block. As will be presented in Section 3.2, this block uses the extra degree of freedom granted by the use of two servovalves to maximize the force range of the cylinder. To the best of the authors' knowledge, this is the only control architecture that uses an extra servovavalve to enhance a system propriety other than energy consumption. Another original feature of this controller is the use of inverse servovalve models. In fact, as presented in Section 2.2.1, these models enable the force control variable to be the mass flow each servovalve must provide, thus separating the nonlinearities of the force dynamics from the nonlinearities of the servovalve model. All these features concur to a higher controller performance as will be shown in Section 4.

\subsection{Force controller}

Each chamber force controller has two control loops as presented in Fig. 6. The inner loop contains a nonlinear state feedback [19] controller in order to linearize the force dynamics. The control laws were synthesized using the pressure dynamic model given by Eqs. 9 and 10, leading to Eqs. 14 and 15.

Fig. 5 Controller architecture

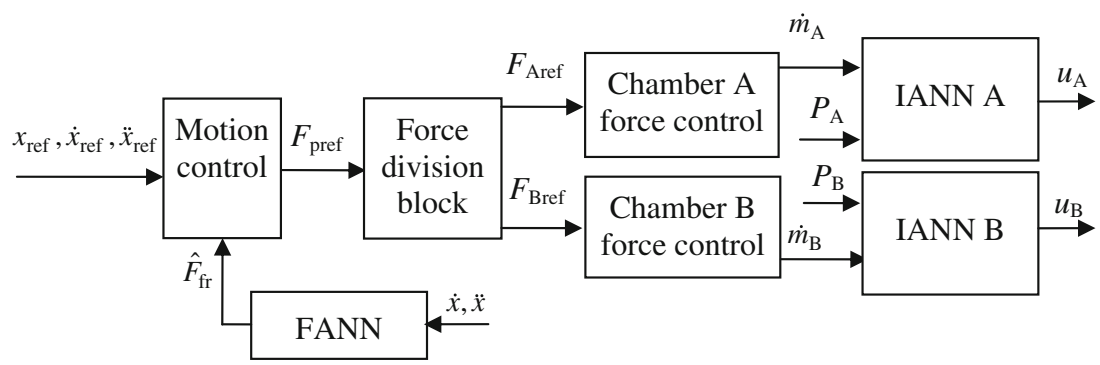




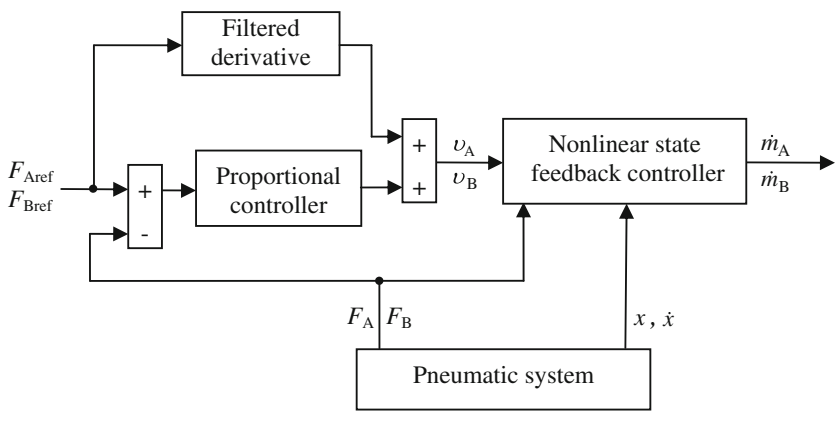

Fig. 6 Force control in each chamber

The outer loop is based on a proportional control action Feed forward of the filtered derivative of the force reference was used in order to increase the bandwidth of the closed loop force dynamics. Equations 12 to 15, where $s$ denotes the Laplace transform operator, present the final control laws obtained.

$v_{\mathrm{A}}=k_{\mathrm{pFA}}\left(F_{\text {Aref }}-F_{\mathrm{A}}\right)+\frac{s}{s / \omega_{\mathrm{FA}}+1} F_{\text {Aref }}$

$v_{\mathrm{B}}=k_{\mathrm{pFB}}\left(F_{\mathrm{Bref}}-F_{\mathrm{B}}\right)+\frac{s}{s / \omega_{\mathrm{FB}}+1} F_{\text {Bref }}$

$\dot{m}_{\mathrm{A}}=\frac{x+x_{\mathrm{Am}}}{\gamma R T_{\mathrm{A}}}\left[v_{\mathrm{A}}+\frac{\gamma \dot{x}}{x+x_{\mathrm{Am}}} F_{\mathrm{A}}-\frac{\gamma-1}{x+x_{\mathrm{Am}}} k_{0}\left(T_{\mathrm{amb}}-T_{\mathrm{A}}\right)\right]$

$$
\dot{m}_{\mathrm{B}}=\frac{x_{\mathrm{Bm}}-x}{\gamma R T_{\mathrm{B}}}\left[v_{\mathrm{B}}-\frac{\gamma \dot{x}}{x_{\mathrm{Bm}}-x} F_{\mathrm{B}}-\frac{\gamma-1}{x_{\mathrm{Bm}}-x} k_{0}\left(T_{\mathrm{amb}}-T_{\mathrm{B}}\right)\right]
$$

With

$x_{\mathrm{Am}}=l / 2+V_{\mathrm{Ad}} / A_{\mathrm{A}}$

$x_{\mathrm{Bm}}=l / 2+V_{\mathrm{Bd}} / A_{\mathrm{B}}$

where $V_{\mathrm{Ad}}$ and $V_{\mathrm{Bd}}$ represent chamber $\mathrm{A}$ and $\mathrm{B}$ dead volumes, respectively, and $T_{\mathrm{A}}$ and $T_{\mathrm{B}}$ are calculated using (9).

\subsection{Force division block}

The use of two servovalves allows an extra degree of freedom that can be used to enhance the system performance. For instance, in [40] and [41] two servovalves were used in order to reduce the energy consumption, a critical factor in autonomous pneumatic systems. On the contrary, the use of an energy driven force division policy is not straightforward in the present case since it necessarily implies a reduction of the equilibrium pressures and therefore a decrease in the cylinder stiffness. The policy followed in this work tries to maximize the force range of the cylinder by avoiding force saturation of the cylinder chambers. Notice that the available pneumatic force inside a pneumatic cylinder chamber is dependent not only on the maximum available
Fig. 7 Range of pneumatic forces in each cylinder chamber

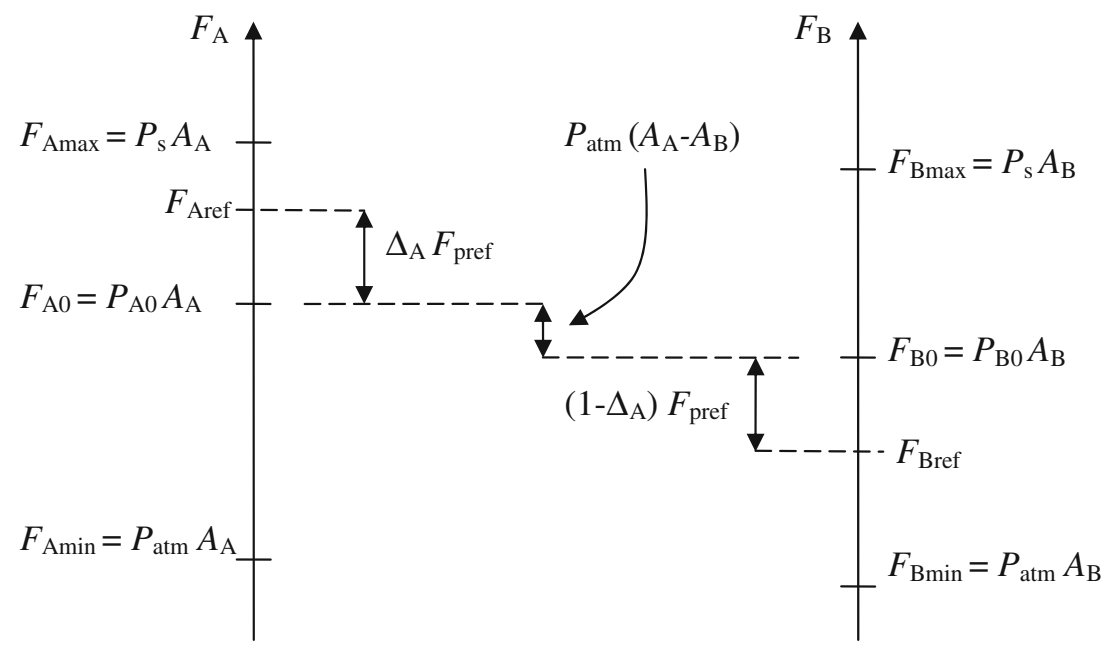


pressure but also on the piston velocity. In fact, at steady state conditions, Eq. 10 can be written for each chamber as:

$\frac{\dot{x} F_{\mathrm{A}}}{R T_{\mathrm{A}}}=\dot{m}_{\mathrm{A}}$

for chamber $\mathrm{A}$ and as

$-\frac{\dot{x} F_{\mathrm{B}}}{R T_{\mathrm{B}}}=\dot{m}_{\mathrm{B}}$

for chamber B. Equations 18 and 19 show that for a given mass flow, the available pneumatic force decreases with an increase of velocity. This effect cannot nevertheless be included in a force division policy since the mass flow itself depends on the working pressure. Consequently, it is only possible to take into account the effect of the maximum positive and negative available pneumatic forces $F_{\mathrm{p} \max }^{+}$and $F_{\mathrm{p} \text { max }}^{-}$:

$$
\begin{aligned}
F_{\mathrm{p} \max }^{+} & =F_{\mathrm{A} \max }-F_{\mathrm{Bmin}}-P_{\mathrm{atm}}\left(A_{\mathrm{A}}-A_{\mathrm{B}}\right) \\
& =\left(P_{\mathrm{s}}-P_{\mathrm{atm}}\right) A_{\mathrm{A}}
\end{aligned}
$$

$$
\begin{aligned}
F_{\mathrm{p} \text { max }}^{-} & =F_{\mathrm{Bmax}}-F_{\mathrm{Amin}}+P_{\mathrm{atm}}\left(A_{\mathrm{A}}-A_{\mathrm{B}}\right) \\
& =\left(P_{\mathrm{s}}-P_{\mathrm{atm}}\right) A_{\mathrm{B}}
\end{aligned}
$$

where $F_{\mathrm{Amax}}, F_{\mathrm{Bmax}}, F_{\mathrm{Bmin}}$, and $F_{\mathrm{Amin}}$ are represented in the diagrams of Fig. 7.

For positive force references $F_{\text {pref, }}$, define the force developed by chamber $\mathrm{A}\left(F_{\mathrm{Aref}}\right)$ as a fraction $\Delta_{\mathrm{A}}$ of the total force $F_{\text {pref }}$ plus an equilibrium force $F_{\mathrm{A} 0}=P_{\mathrm{A} 0} A_{\mathrm{A}}$ (cf. Fig. 7). For $F_{\text {pref }}<0$, define the force developed by chamber $\mathrm{B}\left(F_{\mathrm{Bref}}\right)$ as an equilibrium force $F_{\mathrm{B} 0}=P_{\mathrm{B} 0} A_{\mathrm{B}}$ minus a fraction $\Delta_{\mathrm{B}}$ of the total force $F_{\text {pref: }}$ :

$$
F_{\text {Aref }}=\Delta_{\mathrm{A}} F_{\text {pref }}+F_{\mathrm{A} 0}, F_{\text {pref }}>0
$$

$F_{\text {Bref }}=F_{\text {B } 0}-\Delta_{\mathrm{B}} F_{\text {pref }}, F_{\text {pref }}<0$

To ensure that positive pneumatic force references are accomplished, the force developed by chamber B
$\left(F_{\mathrm{Bref}}\right)$ around the equilibrium force $F_{\mathrm{B} 0}=P_{\mathrm{B} 0} A_{\mathrm{B}}$ is defined as:

$F_{\text {Bref }}=-\left(1-\Delta_{\mathrm{A}}\right) F_{\text {pref }}+P_{\mathrm{B} 0} A_{\mathrm{B}}$

In a similar way, to ensure that negative pneumatic force references are accomplished, the force developed by chamber A $\left(F_{\mathrm{Aref}}\right)$ around the equilibrium force $F_{\mathrm{A} 0}=P_{\mathrm{A} 0} A_{\mathrm{A}}$ must be defined as:

$F_{\text {Aref }}=\left(1-\Delta_{\mathrm{B}}\right) F_{\text {pref }}+P_{\mathrm{A} 0} A_{\mathrm{A}}$

If $\Delta_{\mathrm{A}}$ is high, then for positive pneumatic force references it is likely that chamber A saturates. Similarly, if $\Delta_{\mathrm{B}}$ is high, then for negative pneumatic force references it is likely that chamber B saturates. One way to avoid saturation is to ensure that conditions (26), (27), (28), and (29) hold:

$\left.F_{\text {Aref }}\right|_{F_{\text {pref }}=F_{\text {pmax }}^{+}}=\Delta_{\mathrm{A}} F_{\text {pmax }}^{+}+F_{\mathrm{A} 0} \leq F_{\text {Amax }}$

$\left.F_{\text {Bref }}\right|_{F_{\text {pref }}=F_{\text {pmax }}^{+}}=-\left(1-\Delta_{\mathrm{A}}\right) F_{\text {pmax }}^{+}+P_{\mathrm{B} 0} A_{\mathrm{B}} \geq F_{\mathrm{Bmin}}$

$\left.F_{\text {Bref }}\right|_{F_{\text {pref }}=F_{\text {pmax }}^{-}}=F_{\mathrm{B} 0}-\Delta_{\mathrm{B}} F_{\text {pmax }}^{-} \leq F_{\text {Bmax }}$

$\left.F_{\text {Aref }}\right|_{F_{\text {pref }}=F_{\text {pmax }}^{-}}=\left(1-\Delta_{\mathrm{B}}\right) F_{\text {pmax }}^{-}+P_{\mathrm{A} 0} A_{\mathrm{A}} \geq F_{\text {Amin }}$

Imposing equality on conditions (26) and (28), the following definitions for $\Delta_{\mathrm{A}}$ and $\Delta_{\mathrm{B}}$ result:

$\Delta_{\mathrm{A}}=\left(P_{\mathrm{S}}-P_{\mathrm{A} 0}\right) A_{\mathrm{A}} / F_{\mathrm{p} \max }^{+}$

$\Delta_{\mathrm{B}}=\left(P_{\mathrm{B} 0}-P_{\mathrm{s}}\right) A_{\mathrm{B}} / F_{\text {pmax }}^{-}$

Notice that substituting (30) and (31) in (27) and (29) ensures the equality condition on these two inequalities. Consequently, for positive force references $F_{\text {pref, }}$ chamber A and $\mathrm{B}$ force references $F_{\mathrm{Aref}}$ and $F_{\mathrm{Bref}}$ are therefore determined using (22) and (24), respectively. For negative force references, $F_{\text {Aref }}$ and $F_{\text {Bref }}$ are determined using (23) and (25), respectively. Equilibrium pressures $P_{\mathrm{A} 0}$ and $P_{\mathrm{B} 0}$ 
where calculated in order to fulfill two conditions: (1) symmetry around the pressure range average value $(P=$ $4 \times 10^{5} \mathrm{~Pa}$ ) and (2) static force equilibrium. The final values obtained where $P_{\mathrm{A} 0}=3.78 \times 10^{5} \mathrm{~Pa}$ and $P_{\mathrm{B} 0}=4.22 \times$ $10^{5} \mathrm{~Pa}$.

\subsection{Motion controller}

The motion controller is a variable structure controller with an adjustable thickness boundary layer $\phi$ around the switching surface $\sigma$ in order to reduce chattering. Applying the classical VSC approach presented in [19] to system (6), the following control law results:

$F_{\text {pref }}=\widehat{M}\left(\ddot{x}_{\text {ref }}-\frac{\widehat{F}_{\mathrm{fr}}}{\widehat{M}}+2 \Lambda \dot{e}+\Lambda^{2} e+k_{\mathrm{vsc}} \operatorname{sat}\left(\frac{\sigma}{\phi}\right)\right)$

with the moving mass estimate $\widehat{M}$ defined as:

$\widehat{M}=\left(M_{\max } M_{\min }\right)^{1 / 2}$

where $M_{\min }$ and $M_{\max }$ are the minimum and maximum mass bounds of the system, respectively. The motion following errors are defined by

$e=x_{\text {ref }}-x$

$\dot{e}=\dot{x}_{\mathrm{ref}}-\dot{x}$

and $k_{\mathrm{vsc}}$ is the discontinuous component gain that must conform Eq. 36 so that attractiveness to the boundary layer is ensured [19].

$k_{\mathrm{vsc}}>(\beta-1)\left|\ddot{x}_{\mathrm{ref}}+2 \Lambda \dot{e}+\Lambda^{2} e\right|+\frac{1}{\widehat{M}}\left|e_{\mathrm{fr}}\right|_{\max }+\eta \beta$

In Eq. $36\left|e_{\mathrm{fr}}\right|_{\max }$ is the absolute maximum error of the friction force prediction and $\beta$ is dependent on the uncertainty on the moving mass of the system:

$\beta=\left(\frac{M_{\max }}{M_{\min }}\right)^{1 / 2}$
The sliding surface used in this particular work is defined by Eq. 38 .

$\sigma=\dot{e}+2 \Lambda e+\Lambda^{2} \int_{0}^{t} e d r=0$

An interesting feature of the boundary layer thickness variation law used in this work (see Eq. 39) is that it varies according to the approach angle $\theta$ of the system state to the sliding surface, as explained in detail in [42].

$\phi=\phi_{\min }+k_{\theta}|\theta|$

\section{Experimental results}

In order to establish the performance of the controller developed in this work, several trajectory following tasks were tested with three different loads: $M=M_{\min }=2.69 \mathrm{~kg}, M=$ $M_{\text {med }}=5.9 \mathrm{~kg}$, and $M=M_{\max }=13.1 \mathrm{~kg}$. The position reference is a sinusoid with amplitude of $0.16 \mathrm{~m}$ and a progressively increasing frequency at a rate of $0.0286 \times \pi \mathrm{rads}^{-1} / \mathrm{s}$ (up to ca. $\pi \mathrm{rad} / \mathrm{s})$. For the sake of comparison, the trajectories following tasks were tested not only with the controller developed in this work but also with two reference controllers: a PID and a state feedback controller, presented in the next section.

\subsection{Datum controllers}

Both reference controllers where tuned for the minimum mass configuration as this leads to the system maximum bandwidth. Furthermore, symmetrical control actions were applied to the servovalves, i.e., $u_{\mathrm{A}}=-u_{\mathrm{B}}$. The PID was tuned in two steps: first the Ziegler Nichols rules [43] where applied and then a fine experimental adjustment was performed. The final controller parameters are presented in Table 2.

Table 2 PID and SF controller parameters

\begin{tabular}{llll}
\hline PID & $k_{\mathrm{p}}=25.2 \mathrm{Vm}^{-1}$ & $T_{\mathrm{d}}=0.02 \mathrm{~s}$ & $T_{\mathrm{i}}=0.08 \mathrm{~s}$ \\
$\mathrm{SF}$ & $k_{1}=462.7 \mathrm{Vm}^{-1}$ & $k_{2}=12.9 \mathrm{Vm}^{-1} \mathrm{~s}$ & $k_{3}=0.15 \mathrm{Vm}^{-1} \mathrm{~s}^{2}$ \\
\hline
\end{tabular}


Fig. 8 Tracking results for the PID and SF controller: $M=M_{\min }$
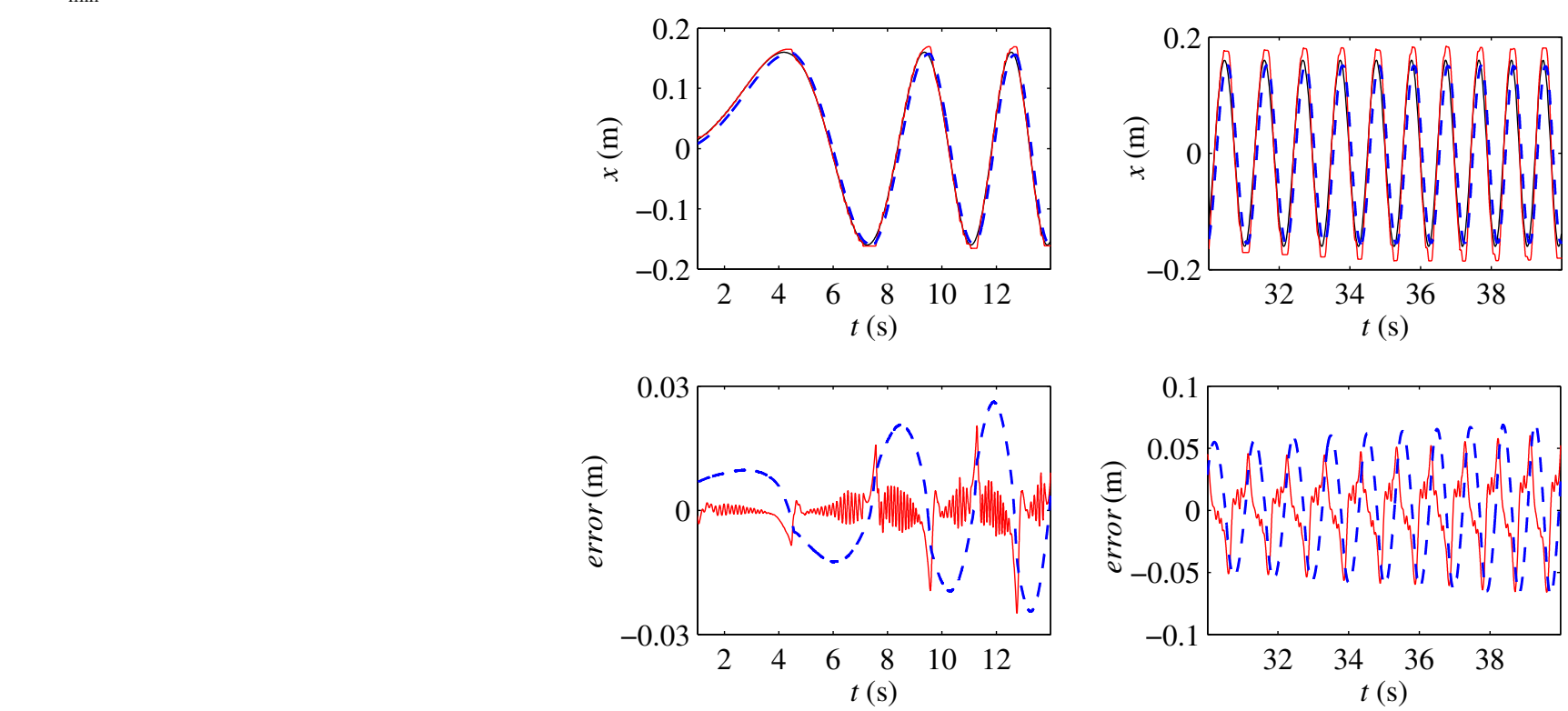

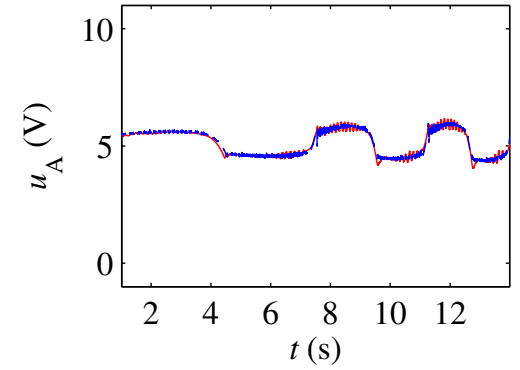

a) $\omega<\pi / 2 \mathrm{rads}^{-1}$

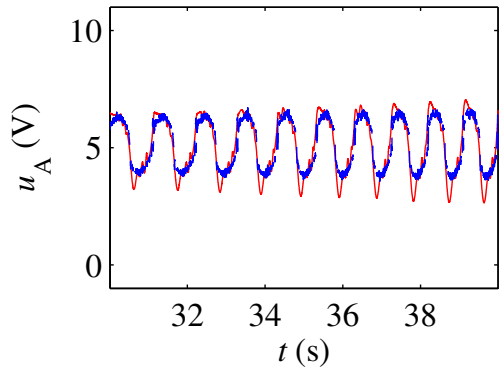

b) $5 \pi / 6<\omega<\pi \operatorname{rads}^{-1}$
In order to account for velocity and acceleration information, a state feedback (SF) controller was also developed. The SF parameters where determined with the pole placement technique [43], using an experimentally identified third-order linearized model of the system, presented in Eq. 40, with $k_{\text {lin }}=0.72 \mathrm{~m} \mathrm{~s}^{-1} \mathrm{~V}^{-1}, \omega_{\mathrm{n}}=$ $39.2 \mathrm{rads}^{-1}$ and $\xi=0.39$.

$\frac{Y(s)}{U_{\mathrm{A}}(s)}=\frac{k_{\operatorname{lin}} \omega_{\mathrm{n}}^{2}}{s\left(s^{2}+2 \xi \omega_{\mathrm{n}} s+\omega_{\mathrm{n}}^{2}\right)}$

The closed loop poles were determined so that the system presents the behavior of a Bessel filter [44] as this provides an approximately constant temporal delay between reference and actual position. Acceleration was measured using the accelerometer of the system (cf.

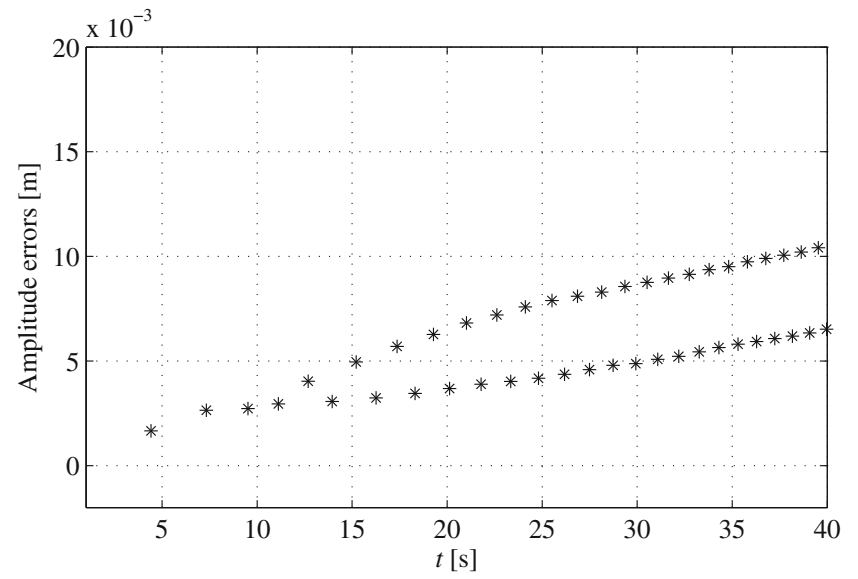

Fig. 9 Amplitude errors for the SF controller with $M=M_{\text {min }}$ 
Fig. 10 Tracking results for the PID and SF controller: $M=M_{\text {med }}$

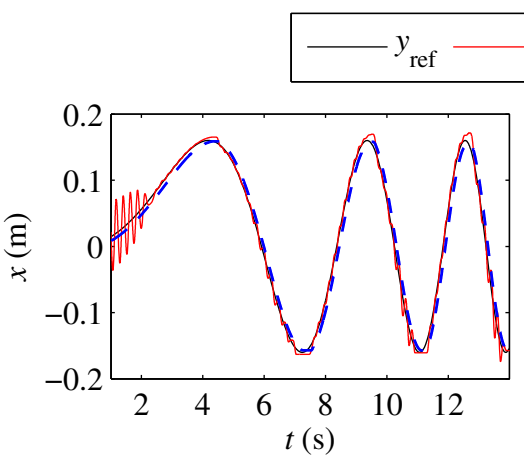

PID - - - SF
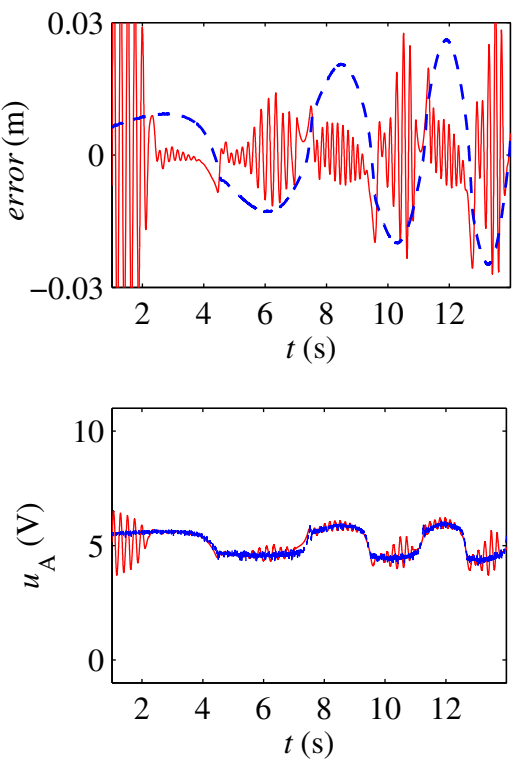

a) $\omega<\pi / 2 \operatorname{rads}^{-1}$
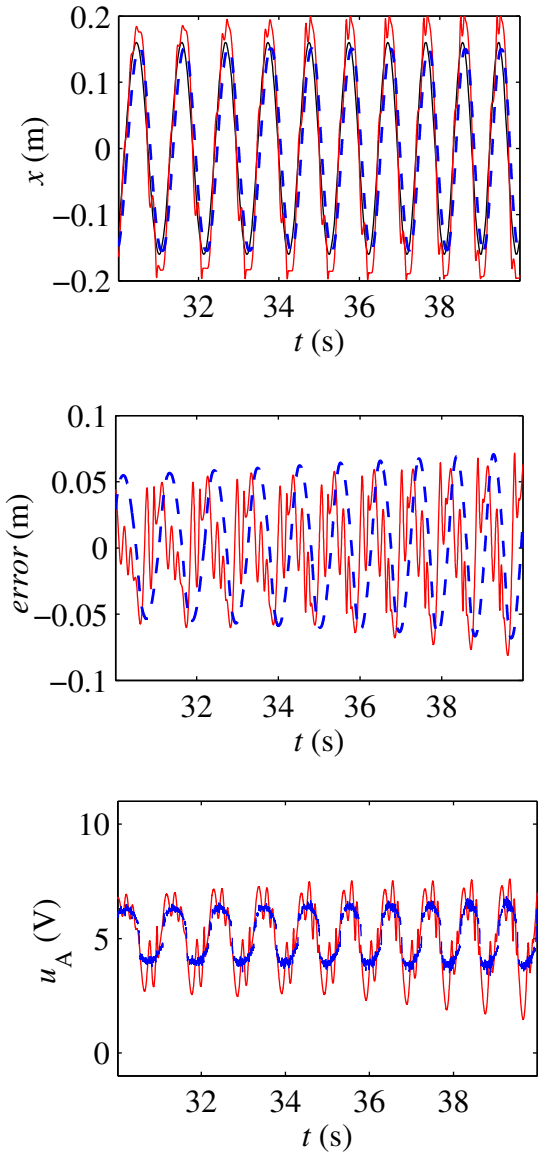

b) $5 \pi / 6<\omega<\pi \operatorname{rads}^{-1}$
Section 2.1) and velocity was measured using a state observer as presented in [45]. Table 2 resumes the SF parameters.

Figures 8 and 9 present results of the PID and SF controllers for $M_{\min }$, Fig. 10 for $M_{\text {med }}$, and Fig. $11 M_{\max }$. Notice that with the PID and $M=M_{\max }$, the piston collided several times with the cylinder heads so the trial was stopped after only ca. $10 \mathrm{~s}$. Regarding the PID results, it is possible to see that for $M=M_{\min }$ the maximum following error is ca. $15 \mathrm{~mm}$ for low frequencies and ca. $50 \mathrm{~mm}$ for higher frequencies. The maximum error occurs mainly when velocity changes sign, emphasizing the important role that static friction plays in the system. The PID performance when $M=M_{\text {med }}$ and $M=M_{\max }$ is significantly deteriorated, a fact that is expected since the PID does not accommodate significant parameter variation. These trials highlight the need of a PID retuning for each different mass used. Concerning the SF controller, overall results are clearly better than the ones obtained with the PID, revealing the importance of velocity and acceleration feedback. In order to remove the influence of the time delays between reference and measured positions from the analysis, Fig. 9 presents the errors between the amplitude values of $x_{\text {ref }}$ and the amplitude values of $x$ for the trial of Fig. 8. It can be seen that the error ranges from ca. $2 \mathrm{~mm}$ to ca. $10 \mathrm{~mm}$ and steadily increases with frequency. Another noticeable feature is that the SF controller results appear to be highly independent of the load for the frequency range considered. This fact may once again be justified by the existence velocity and acceleration feedback. 
Fig. 11 Tracking results for the PID and SF controller: $M=M_{\max }$
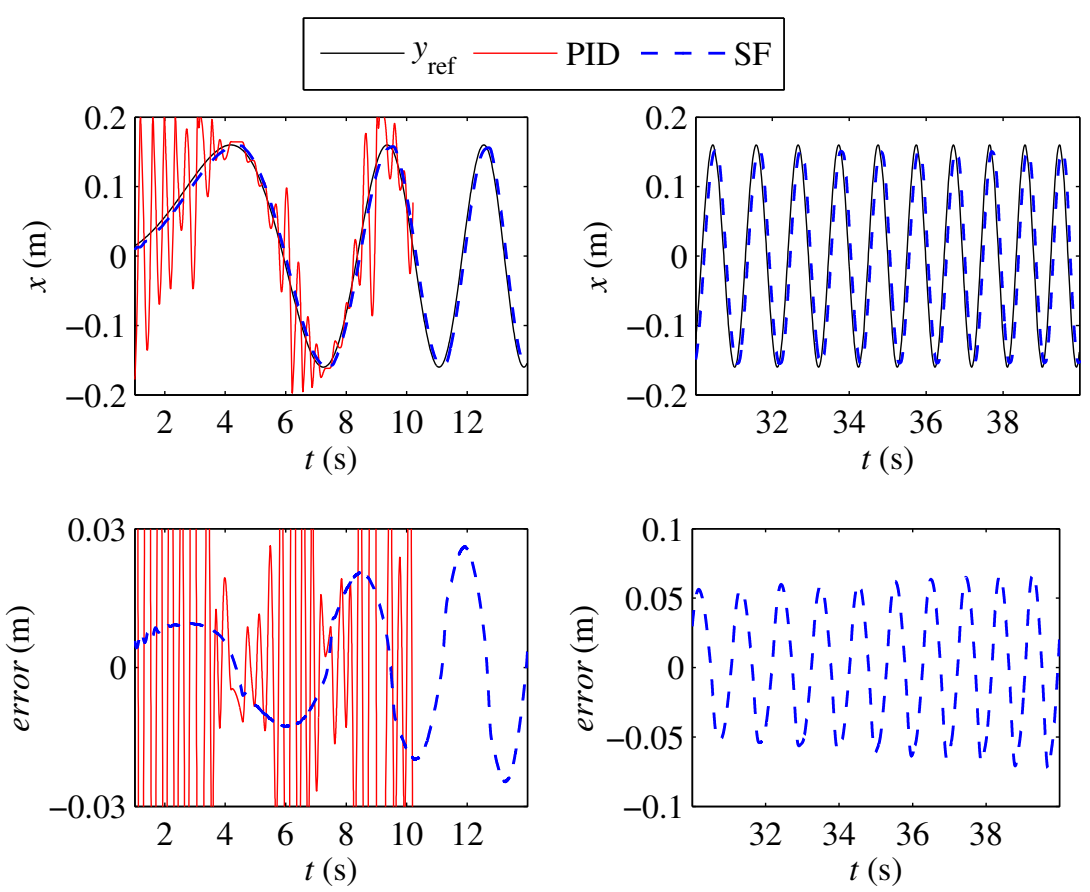

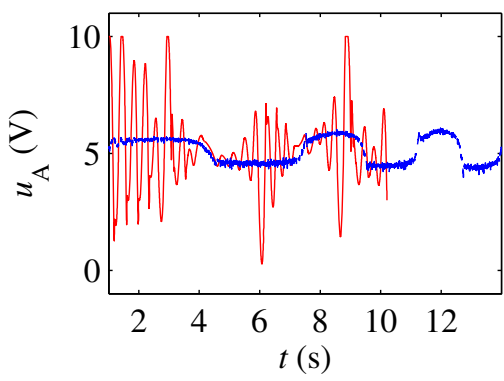

a) $\omega<\pi / 2 \operatorname{rads}^{-1}$

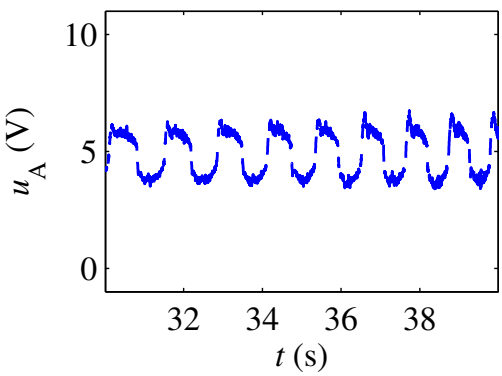

b) $5 \pi / 6<\omega<\pi \operatorname{rads}^{-1}$

\subsection{Controller developed in this work}

The parameters of the controller developed in this work were experimentally tuned for $M_{\text {med }}$ and held constant during the trials. Figures 12 and 13 present the results for $M_{\min }$, Fig. 14 for $M_{\text {med }}$ and Fig. 15 for $M_{\max }$. Figures 12, 14 and 15 include position, error and control action results. For frequencies up to ca. $\pi / 2 \mathrm{rads}^{-1}$ very good results are obtained since the following error is roughly below $1 \mathrm{~mm}$. As the reference frequency increases the following error becomes larger, namely when the piston changes direction, a result that is probably due to friction effects. Notice, however, that the tracking errors are essentially caused by time delays between the reference and measured position signals. In order to illustrate this, Fig. 13 represents the errors between the amplitude values of $x_{\text {ref }}$ and the amplitude values of $x$ for the trial of Fig. 12. For frequencies up to ca. $\pi / 2$ this error is very low, less than $1 \mathrm{~mm}$, and even for frequencies near $\pi \mathrm{rads}^{-1}$, corresponding to piston velocities ca. $1 \mathrm{~ms}^{-1}$, the amplitude errors are below $2 \mathrm{~mm}$. These amplitude errors compare very favorably with the ones obtained using the state feedback controller (cf. Fig. 9), showing that the controller developed in this work can significantly improve tracking tasks in servopneumatic systems while maintaining a high robustness to load variation. In fact, all these results were performed without any controller retuning 
Fig. 12 Tracking results for the controller developed in this work: $M=M_{\min }$

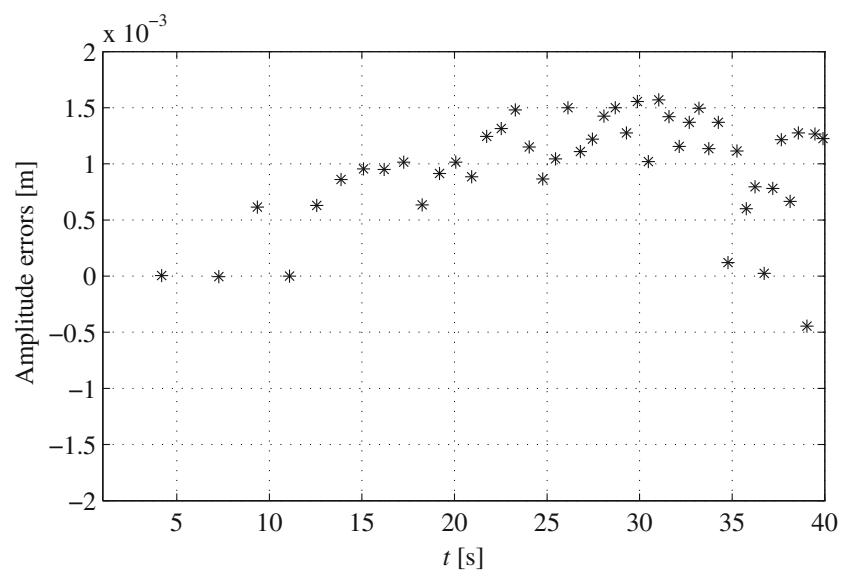

Fig. 13 Amplitude errors for $M=M_{\text {min }}$
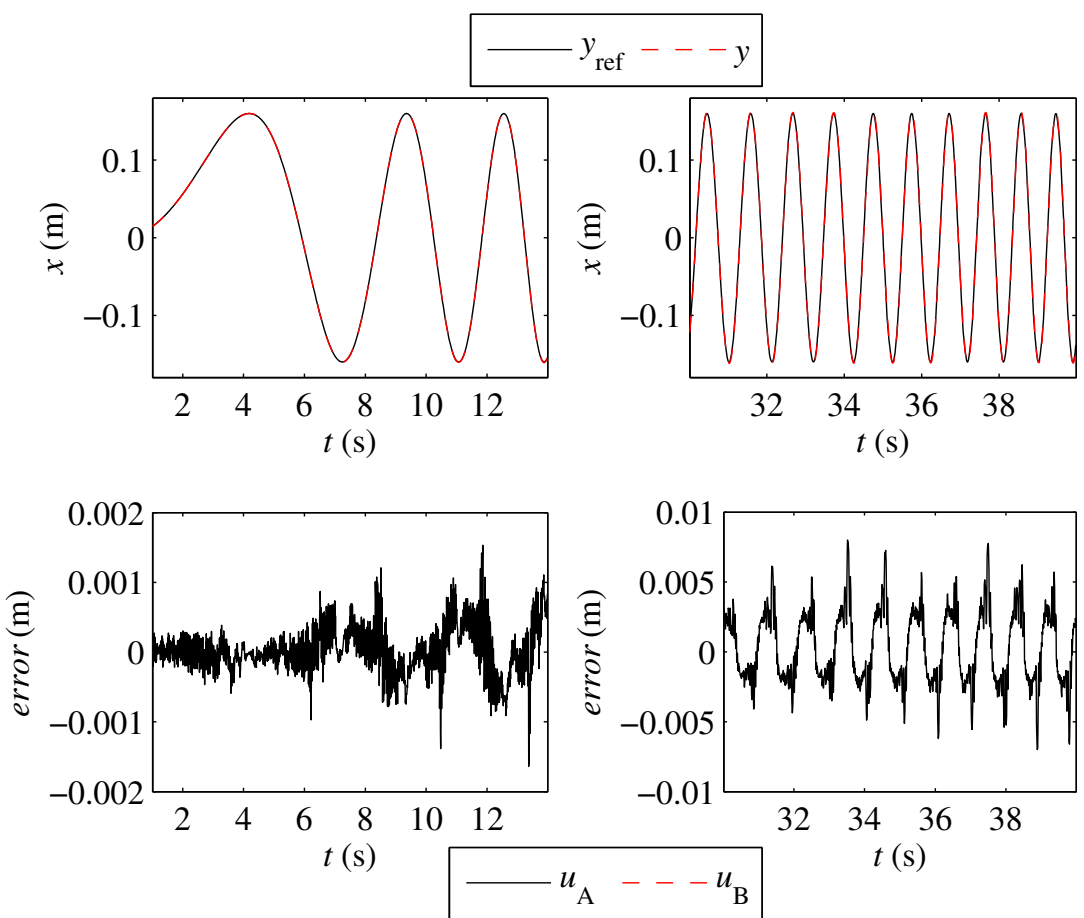

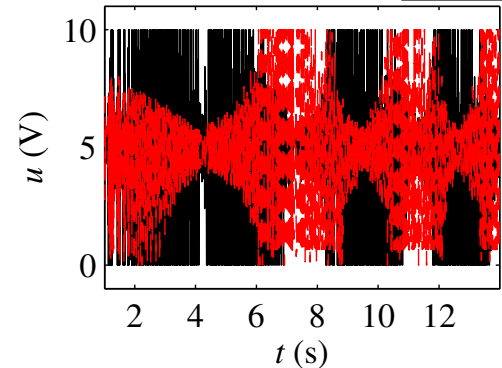

a) $\omega<\pi / 2 \mathrm{rads}^{-1}$

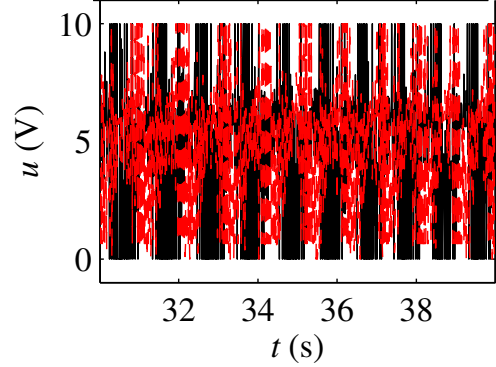

b) $5 \pi / 6<\omega<\pi \mathrm{rads}^{-1}$ although the load varies almost 500\%. Regarding controllers developed in other research studies, a direct comparison is not possible as the reference type, amplitude, and frequency may differ substantially from the ones used in this work. However, and as detailed in Section 1, most studies present following errors in the range between 2 and $10 \mathrm{~mm}$, so it is believed that the results obtained in this work may represent a significant step towards a more ample use of servopneumatic systems in trajectory following industrial applications. A final remark to underline that the results presented in this section are representative of the system performance since similar conclusions were obtained with references of different amplitudes and shapes. 
Fig. 14 Tracking results for the controller developed in this work: $M=M_{\text {med }}$
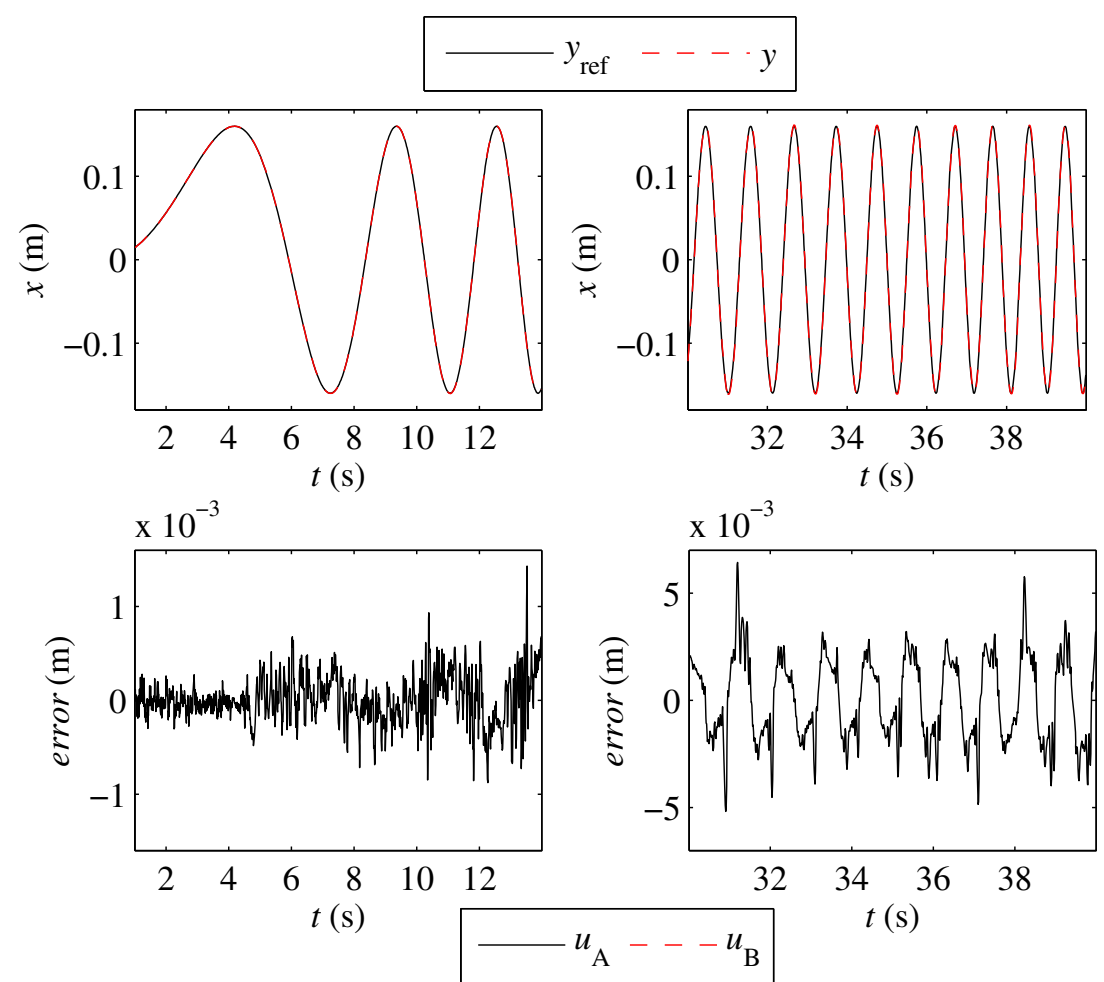

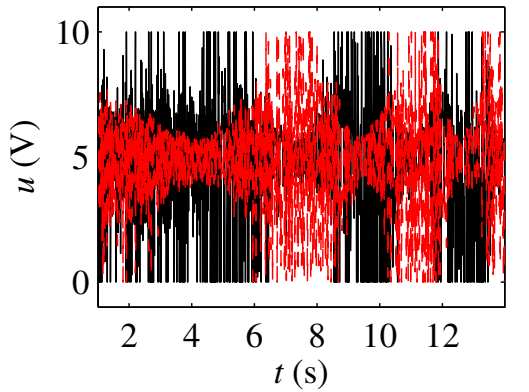

a) $\omega<\pi / 2 \mathrm{rads}^{-1}$

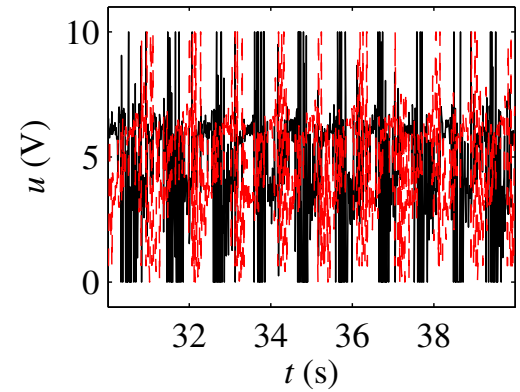

b) $5 \pi / 6<\omega<\pi \operatorname{rads}^{-1}$

\section{Conclusions}

This paper presented an innovative controller for a pneumatic servosystem that achieves high performance in trajectory following tasks. After presenting the neural network-based system model, an original control architecture with three components (motion controller, force division block, and force controller) was developed. The controller performance was subsequently assessed in an experimental setup using standard industrial servopneumatic components. For comparison purposes two datum controllers (PID and state feedback) were also developed and experimentally tested. Results showed that a sinusoidal position reference with varying frequency can be followed, for frequencies up to $\pi \operatorname{rads}^{-1}$ (corresponding to piston velocities of ca. $1 \mathrm{~ms}^{-1}$ ), with errors of only a few millimeters. This performance is much better than the one obtained with the datum controllers and compares very favorably with existing literature results. Furthermore, the controlled system exhibited high robustness to parameter variation since high accuracy results were obtained without any controller retuning even though the payload varied from 2.6 to $13.1 \mathrm{~kg}$. 
Fig. 15 Tracking results for the controller developed in this work: $M=M_{\max }$

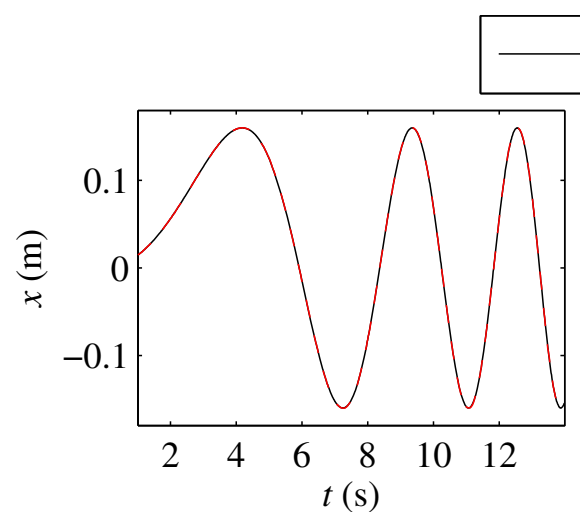

$y_{\text {ref }}--y$

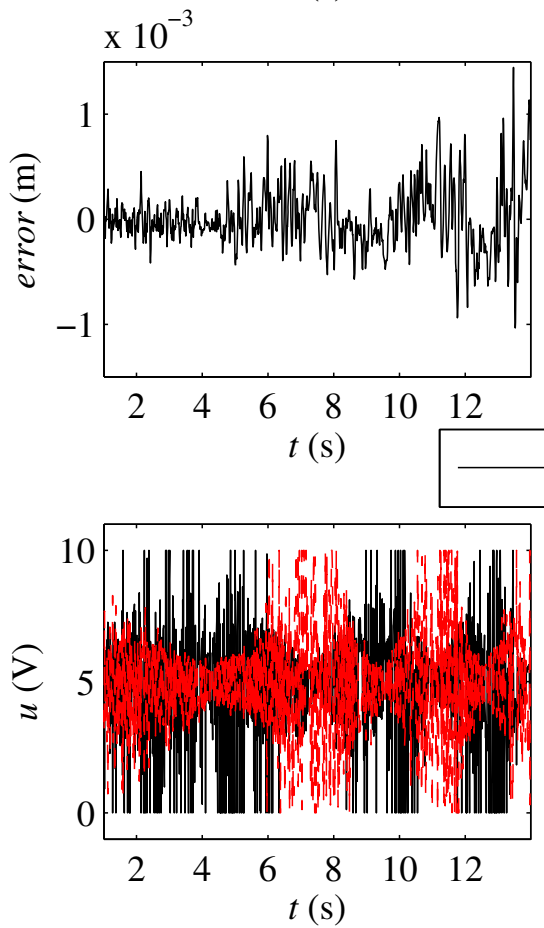

a) $\omega<\pi / 2 \mathrm{rads}^{-1}$
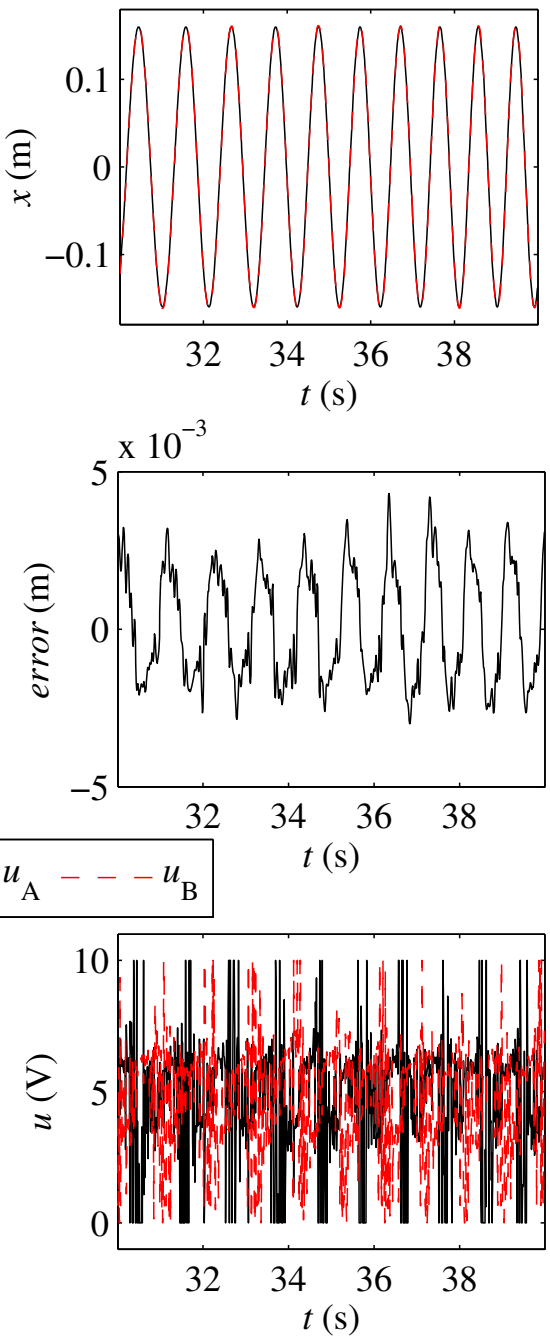

b) $5 \pi / 6<\omega<\pi \mathrm{rads}^{-1}$

\section{References}

1. Kagawa T, Tokashiki L, Fujita T (2000) Accurate positioning of a pneumatic servosystem with air bearings. In: Proc. of the Bath Workshop on Power Transmission and Motion Control, Bath, UK, 2000. pp 257-268

2. Sorli M, Figliolini G, Almondo A (2010) Mechatronic model and experimental validation of a pneumatic servo-solenoid valve. ASME J Dyn Syst, Meas, Control 132(5):054503

3. Richard E, Scavarda S (1996) Comparison between linear and nonlinear control of an electropneumatic servodrive. ASME J Dyn Syst, Meas, Control 118(2):245-252

4. Thomasset D, Scavarda S, Sesmat S, Belgharbi M (1999) Analytical model of the flow stage of a pneumatic servodistributor for simulation and nonlinear control. In: Proc. of the Sixth Scandinavian International Conference on Fluid Power Tampere, Finland, May 26-28 1999. pp 848-860
5. Carneiro JF, Almeida FG (2006) Modeling Pneumatic Servovalves using Neural Networks. In: Proc. of the 2006 IEEE Conference on Computer Aided Control Systems Design, Munich, Germany, 2006. pp 790-795

6. Carneiro JF, Almeida FG (2006) Pneumatic servovalve models using artificial neural networks. In: Johnston N, Edge K (eds) Proc. of the Bath Symposium on Power Transmission and Motion Control. Bath, UK, pp 195-208

7. Karnopp D (1985) Computer simulation of stick-slip friction in mechanical dynamic systems. ASME J Dyn Syst, Meas, Control 107(1):100-107

8. Canudas de Wit C, Olsson H, Astrom K, Lischinsky P (1995) A new model for control of systems with friction. IEEE Transactions on Automatic Control 40(3):419-425

9. Swevers J, Al-Bender F, Ganseman CG, Prajogo T (2000) An integrated friction model structure with improved presliding behavior for accurate friction compensation. IEEE Transactions on Automatic Control 45(4):675-686 
10. Richer E, Hurmuzlu Y (2000) A high performance pneumatic force actuator system: part I-nonlinear mathematical model. ASME J Dyn Syst, Meas, Control 122(3):416-425

11. Carneiro JF, Almeida FG (2006) Reduced order thermodynamic models for servopneumatic actuator chambers. Proc Instn Mech Engrs, Part I, Journal of Systems and Control Engineering 220 (4):301-314

12. Najafi F, Morteza F, Saadat M (2009) Dynamic modelling of servo pneumatic actuators with cushioning. International Journal of Advance Manufacturing Technology 42(7-8):757-765

13. Saleem A, Abdrabbo S, Tutunji T (2009) On-line identification and control of pneumatic servo drives via a mixed-reality environment. International Journal of Advanced Manufacturing Technology 40(5-6):518-530

14. Takosoglu J, Dindorf R, Laski P (2010) Rapid prototyping of fuzzy controller pneumatic servo-system. International Journal of Advanced Manufacturing Systems 40(3-4):349-361

15. Pu J, Weston RH (1988) Motion control of pneumatic drives. Microprocessors and Microsystems 12(7):373-382

16. Ionnidis I, Nguyen T (1986) Microcomputer-controlled servopneumatic drives. In: Seventh International Fluid Power Symposium, September 1986. pp 155-164

17. Ning S, Bone G (2002) High Steady-State Accuracy Pneumatic Servo Positioning System with PVA/PV Control and Friction Compensation. In: Proc. of the 2002 IEEE International Conference on Robotics and Automation, Washington DC, USA, 2002. pp 2824-2829

18. Isidori A (1995) Nonlinear control systems 3rd edn. Springer, New York

19. Slotine JJ, Li W (1991) Applied nonlinear control. Prentice-Hall, New Jersey

20. Outbib R, Richard E (2000) State feedback stabilization of an electropneumatic system. ASME J Dyn Syst, Meas, Control 122 (3):410-415

21. Xiang F, Wikander J (2004) Block-oriented approximate feedback linearization for control of pneumatic actuator system. Control Engineering Practice 12(4):387-399

22. Situm Z, Pavkovic D, Novakovic B (2004) Servo pneumatic position control using fuzzy PID gain scheduling. ASME J Dyn Syst, Meas, Control 126(2):376-387

23. Taghizadeh M, Najafi F, Ghaffari A (2010) Multimodel PDcontrol of a pneumatic actuator under variable loads. Interntional Journal of Advanced Manufacturing Technologies 48:655-662

24. Bobrow JE, Jabbari F (1991) Adaptive pneumatic force actuation and position control. ASME J Dyn Syst, Meas, Control 113 (2):267-272

25. Shih M-C, Shy-I T (1994) Pneumatic servo-cylinder position control by PID-self-tuning controller. Japan Society of Mechanical Engineers International Journal 37(3):565-572

26. Ferraresi C, Giruado P, Quaglia G (1994) Non-conventional adaptive control of a servopneumatic unit for vertical load positioning. In: Proc. of the 46th National Conference on Fluid Power, 1994. pp 319-333

27. Richardson R, Plummer A, Brown M (2001) Self-tuning control of a low-friction pneumatic actuator under the influence of gravity. IEEE Transactions on Control Systems Technology 9 (2):330-334
28. Drakunov S, Hanchin GD, Su WC, Ozguner U (1997) Nonlinear control of a rodless pneumatic servoactuator, or sliding modes versus Coulomb friction. Automatica 33(7):1401-1408

29. Pandian S, Hayakawa Y, Kanazawa Y, Kamoyama Y, Kawamura S (1997) Practical design of a sliding mode controller for pneumatic actuators. ASME J Dyn Syst, Meas, Control 119 (4):666-674

30. Richer E, Hurmuzlu Y (2000) A high performance pneumatic force actuator system: part II-nonlinear controller design. ASME J Dyn Syst, Meas, Control 122(3):426-434

31. Levant A (1993) Sliding order and sliding accuracy in sliding mode control. International Journal of Control 58(6):1247-1263

32. Smaoui M, Brun X, Thomasset D (2004) Robust Position Control of an Electropneumatic System Using Second Order Sliding Mode. In: Proc. of the 2004 IEEE International Symposium on Industrial Electronics, Ajaccio, France, 2004. pp 429-434

33. Junbo S, Xiaoyan B, Ishida Y (1997) An application of MNN trained by MEKA for the position control of pneumatic cylinder. In: Proc. of the IEEE International Conference on Neural Networks, Houston, USA, 1997. pp 829-833

34. Lee HK, Choi GS, Choi GH (2002) A study on tracking position control of pneumatic actuators. Mechatronics 12(6):813-831

35. Varseveld R, Bone GM (1997) Accurate position control of a pneumatic actuator using on/off solenoid valves. IEEE/ASME Transactions on Mechatronics 2(3):195-204

36. Reina G, Giannoccaro NI, Gentile A (2002) Experimental tests on position control of a pneumatic actuator using on/off solenoid valves. In: Proc. of the IEEE International Conference on Industrial Technology, Bangkok, Thailand, 2002. pp 555-559

37. Carneiro JF, Gomes de Almeida F (2011) Pneumatic servo valve models based on artificial neural networks. Proceedings of the Institution of Mechanical Engineers, Part I: Journal of Systems and Control Engineering 225(3):393-411. doi:10.1177/ 2041304110394498

38. Noorgard M, Ravn O, Poulsen NK, Hansen LK (2003) Neural networks for modelling and control of dynamic systems: a practitioner's handbook. Springer Verlag, London

39. Carneiro JF, Almeida FG (2007) Heat transfer evaluation on industrial pneumatic cylinders. Proc Instn Mech Engrs, Part I, Journal of Systems and Control Engineering 221(1):119-128

40. Brun X, Thomasset D, Bideaux E (2002) Influence of the process design on the control strategy: application in electropneumatic field. Control Engineering Practice 10(7):727-735

41. Barth EJ, Goldfarb M, Al-Dakkan KA (2003) Energy Saving Control for Pneumatic Servo Systems. In: Proc. of the 2003 IEEE/ ASME International Conference on Advanced Mechatronics, Kobe, Japan, 2003. pp 284-289

42. Carneiro JF, Almeida FG (2011) Vsc approach angle based boundary layer thickness: a new variation law and its stability proof. In: Accepted for publication on the 2011 Bath/ASME Symposium on Fluid Power and Motion Control, Arlington, VA, 2011.

43. Ogata K (2001) Modern control engineering 4th edn. Prentice Hall,

44. Schaumann R, Valkenburg MEV (2001) Design of analog filters. Oxford University Press, Inc., New York

45. Lopes AM, Almeida FG (2007) Acceleration-based forceimpedance control of a six-dof parallel manipulator. Industrial Robot: An International Journal 34(5):386-399 